\title{
Polypyrrole Coating on Zinc for Corrosion Prevention of Zinc-coated Steels
}

\author{
Sho TSUCHIYA, Mikito UEDA and Toshiaki OHTSUKA \\ Graduate School of Engineering, Hokkaido University, Kita 13 Nishi 8, Kita-ku, Sapporo 060-8628 Japan. \\ E-mail: ohtsuka@elechem1-mc.eng.hokudai.ac.jp
}

(Received on July 18, 2006; accepted on September 14, 2006)

\begin{abstract}
The polypyrrole (PPy) coating was prepared by constant current oxidation on zinc from aqueous solution of sodium tartrate containing sodium molybdate and pyrrole monomer to make new coating for corrosion prevention of zinc-coated steels.

The coating is started with an initial formation of salt layer of zinc tartrate and/nor zinc molybdate during the oxidation. Nucleation and growth of PPy take place on the salt layer in the second stage. The PPy layer thus formed is doped by tartrate ions and/nor molybdate ions, which was confirmed by a depth profile measurement of glow discharge optical emission spectroscopy (GD-OES). The conductance of the coatings was as small as $1 \times 10^{-3} \mathrm{~S} \mathrm{~cm}^{-2}$ for the $5 \mu \mathrm{m}$-thick layer probably due to the formation of the salt layer underneath the PPy layer. Corrosion test of the PPy-coated zinc electrode in $3.5 \mathrm{wt} \% \mathrm{NaCl}$ solution showed that the zinc electrode was passivated and protected over $48 \mathrm{~h}$ by action of the oxidative PPy coating doped by tartrate and molybdate ions.
\end{abstract}

KEY WORDS: polypyrrole; zinc; corrosion prevention; molybdate; tartrate.

\section{Introduction}

Many papers have been recently published for corrosion prevention of metals by use of conducting polymer coatings, in which oxidative conducting polymers such as polyaniline (PANI) and polypyrrole (PPy) induced passivation of substrate metals. DeBerry was the first to point out the possibility for the conducting polymer coating to protect metals against corrosion. ${ }^{1)}$ He reported that stainless steel covered by PANI layer was kept passive state in sulfuric acid solution for long time period. Other authors also presented the corrosion prevention of stainless steel by PANI coating ${ }^{2-4)}$ as well as PPy coating. ${ }^{5,6)}$ Since the conducting polymer coatings could be electrochemically formed on various metals, ${ }^{7,8)}$ they were applied to corrosion prevention of the metals of $\mathrm{Cu},{ }^{9)} \mathrm{Zn},{ }^{10)} \mathrm{Al},{ }^{11)} \mathrm{Ti},{ }^{12)} \mathrm{CuNi} .{ }^{13)}$

As zinc is one of less noble metals, the oxidative PPy formation may not be easy, because the electrochemical oxidation induces anodic dissolution of zinc before the PPy formation. Zeid et al. presented electrochemical formation of PPy layer on zinc from solution containing $0.1 \mathrm{M}$ sodium oxalate and $0.9 \mathrm{M}$ pyrrole monomer after zinc was protected by treatment of immersion in $0.2 \mathrm{M} \mathrm{Na}_{2} \mathrm{~S} .{ }^{14)}$ Petitjean reported that PPy layer was anodically formed on zinc in $1 \mathrm{M}$ sodium salicylate solution containing $0.5 \mathrm{M}$ pyrrole monomer without any pretreatment. ${ }^{15)}$ Martins et al. recently succeeded electrochemical formation of PPy layer on zinc from $0.2 \mathrm{M}$ sodium tartrate solution containing $0.5 \mathrm{M}$ pyrrole monomer. ${ }^{16}$ They claimed that the PPy layer formed in tartrate solution was more homogeneous and better adhesion than that in salicylate solution.
In the previous paper we successfully prepared PPy layer on steels in molybdo-phosphate solution to prevent the corrosion of the steels in aqueous solution. ${ }^{17)}$ In the present paper, we present that the homogeneous PPy coating is formed on zinc electrodes in tartrate solution. For improvement of corrosion prevention of zinc by the PPy layer, we further prepare a PPy coating doped by molybdate ions with tartrate ions. It was found that the doping of molybdate ions introduced the higher conductive and more protective PPy layer.

\section{Experimental}

A pure zinc plate $1 \mathrm{~mm}$ thick was used, which was purchased from Johnson-Matthy. The zinc plate was cut to $20 \times 10 \mathrm{~mm}$, then polished by \#800 SiC paper, and degreased in acetone in ultrasonic washer.

The pyrrole monomer was purchased from Kanto Chemical (purity 99\%). Other electrolytes were prepared from analytical grade reagents and Millipore pure water. The electrolytes were deaerated by passing pure nitrogen before use.

For formation of the PPy coating, various aqueous solutions containing pyrrole monomer were used which were listed in Table 1. The zinc plate was electrochemically oxidized by constant current in these solutions. Conductance of the PPy coating was measured by AC impedance for which two gold disc electrodes with $10 \mathrm{~mm}$ diameter was pressed from both side by springs and $0.01 \mathrm{~V}$ AC potential was applied between the gold electrodes.

The zinc coated by the PPy coating was immersed for $7 \mathrm{~d}$ in $3.5 \mathrm{wt} \% \mathrm{NaCl}$ aqueous solutions at $\mathrm{pH} 5.3$ to examine 
Table 1. Formation of PPy layer in various aqueous solutions by constant current oxidation at $15 \mathrm{~mA} \mathrm{~cm}^{-2}$.

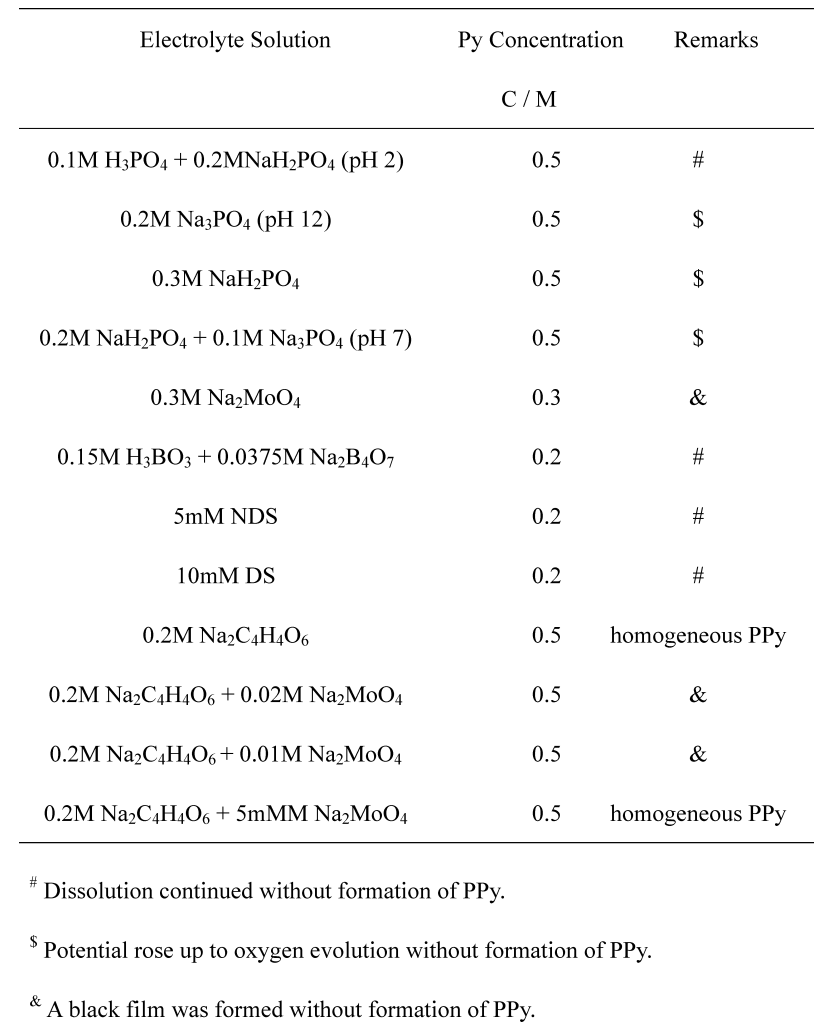

the protection performance of the PPy coating for the corrosion of zinc. The corrosion potential was recorded during the immersion. The immersion area was restricted to $\left(10 \times 10 \mathrm{~mm}^{2}\right) \times 2$ by masking the edge parts with silicon resin.

Thickness of the PPy coating was evaluated from the cross-sectional view of the PPy-coated zinc by SEM. Surface morphology of the PPy coated zinc was observed by conventional optical microscopy equipped with a CCD camera.

The elemental analysis in depth was made by glow discharge optical emission spectroscopy (GD-OES), Horiba JY-5000RF.

\section{Results}

\subsection{Preparation of PPy Coating}

PPy formation with constant current was tried in various aqueous solutions listed in Table 1. The formation of PPy layer was not succeeded in the solutions except for the tartrate solution, because the continuous anodic dissolution took place and potential did not reach the PPy layer formation, or the insulating film continued to form, followed by oxygen evolution on the surface. A black homogeneous layer of PPy was formed only in the tartrate solution.

Figure 1 shows potential transient during by constant current oxidation from 10 to $25 \mathrm{~mA} \mathrm{~cm}^{-2}$ in $0.2 \mathrm{M}$ sodium tartrate solution containing $0.5 \mathrm{M}$ pyrrole monomer. The potential initially exhibits a plateau at -0.8 to $-0.7 \mathrm{~V}$, followed by a peak, and then the second plateau. The black layer of PPy was observed at the second potential plateau. The plateau potentials and the peak potential increase with increase of CD. According the Martins et al., zinc salt layer

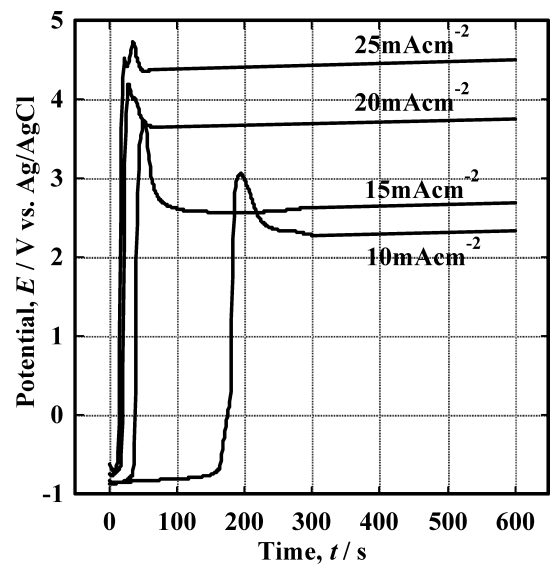

Fig. 1. Potential transient with time during constant current oxidation from 10 to $25 \mathrm{~mA} \mathrm{~cm}^{-2}$ in $0.2 \mathrm{M}$ sodium tartrate solution containing $0.5 \mathrm{M}$ Py monomer.

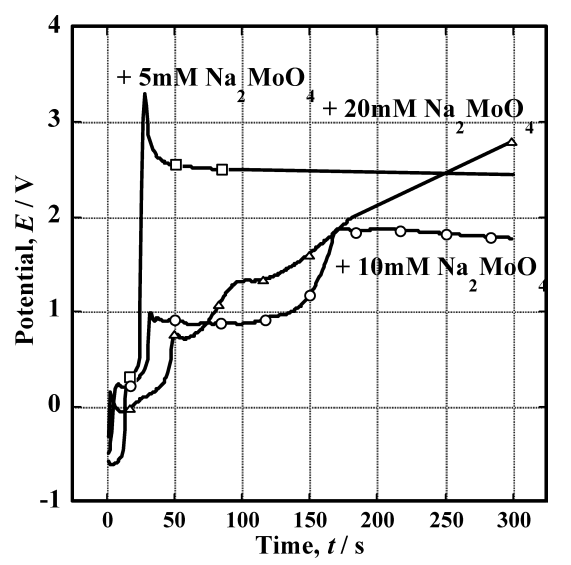

Fig. 2. Potential transient with time during constant current oxidation at $15 \mathrm{~mA} \mathrm{~cm}^{-2}$ in $0.2 \mathrm{M}$ sodium tartrate solution containing $0.5 \mathrm{M}$ Py monomer and sodium molybdate at concentrations of 5,10 , and $20 \mathrm{mM}$.

consisting of zinc tartrate may be formed during the initial plateau to passivate zinc surface. The initial peak after the salt layer formation may correspond to nucleation of PPy layer on the salt layer, followed by three-dimensional growth during the second plateau. At $\mathrm{CD}$ lower than $10 \mathrm{~mA} \mathrm{~cm}^{-2}$, the potential did not rise to potential of PPy formation; dissolution of zinc continued and white precipitate formed on zinc electrode.

When one mixed the sodium tartrate solution with sodium molybdate, the potential transient for PPy layer formation was greatly changed. Figure 2 shows the potential transient in the mixed solution containing $0.5 \mathrm{M}$ pyrrole monomer at constant $\mathrm{CD}$ of $15 \mathrm{~mA} \mathrm{~cm}^{-2}$. Only in the solution containing sodium molybdate at the lower concentration than $5 \mathrm{mM}$, PPy layer is formed after the potential peak at which nucleation of PPy may take place. In the solutions at the higher concentration of sodium molybdate, a black film that was supposed to be zinc molybdate was formed and homogeneous PPy was not observed.

Figure 3 shows potential transient at $15 \mathrm{~mA} \mathrm{~cm}^{-2}$ in tartrate solution and tartrate solution containing molybdate. There is difference between the initial potential plateaus in the solutions. In the solution containing molybdate, the time period of the plateau is shortened and another plateau 


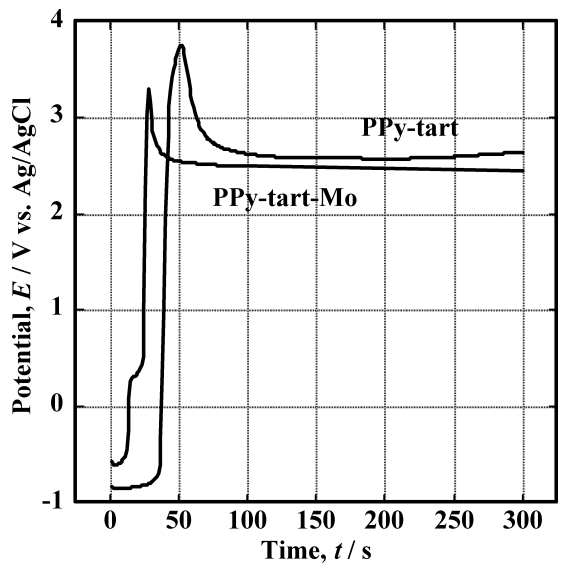

Fig. 3. Potential transient with time during constant current oxidation at $15 \mathrm{~mA} \mathrm{~cm}^{-2}$ in $0.2 \mathrm{M}$ sodium tartrate solution containing $0.5 \mathrm{M}$ Py monomer and/nor sodium molybdate at concentrations of $5 \mathrm{mM}$.

appears at about $0.3 \mathrm{~V}$. The new plateau may correspond to formation of zinc molybdate layer. After the potential peak, the PPy layer growth occurs by almost same manner as that in the solution without molybdate.

\subsection{Characterization of the PPy Coating}

Figure 4 shows optical microscopic view of the PPy coating formed on zinc in $0.2 \mathrm{M}$ tartrate solution containing $5 \mathrm{mM}$ molybdate and $0.5 \mathrm{M}$ pyrrole monomer. In Fig. 4(A) the PPy coating was formed by one-step oxidation at $15 \mathrm{~mA} \mathrm{~cm}^{-2}$ for $300 \mathrm{~s}$. In Fig. 4(B), galvanostatic oxidation was carried out by two steps; first, the oxidation at $15 \mathrm{~mA} \mathrm{~cm}^{-2}$ for $100 \mathrm{~s}$ and second, at $1.0 \mathrm{~mA} \mathrm{~cm}^{-2}$ for $3000 \mathrm{~s}$. Total electricity was same at $4.5 \mathrm{C} \mathrm{cm}^{-2}$ for the both oxidation. The PPy coating formed at $15 \mathrm{~mA} \mathrm{~cm}^{-2}$, particle diameter is about 5-10 $\mu \mathrm{m}$, however, the PPy coating formed by the two step polymerization consists of smaller particles with diameter less than $5 \mu \mathrm{m}$. From the optical microscopic observation, the PPy film is seen to consist of agglomerates of fine PPy particles. The diameter of the fine particles may depend on Py concentration. The diameter of the fine particles also has a tendency to decrease with the smaller CD. For preparation of the denser PPy film consisting of the finer particles, we adopted the two-step polymerization as shown in Fig. 4(B). In the second step at the lower $\mathrm{CD}$, we believe that the rough coating formed in the first step is filled by finer particles.

Figure 5 shows a cross-sectional SEM view of PPy coating formed in the tartrate solution at $15 \mathrm{~mA} \mathrm{~cm}^{-2}$. The salt layer with thickness about $1 \mu \mathrm{m}$ which may consist of zinc tartrate was observed between zinc substrate and the PPy layer. The outer PPy layer is seen to be $4-5 \mu \mathrm{m}$ thick.

Figure 6 shows GD-OES depth profile of the PPy coating formed at constant $\mathrm{CD}$ of $15 \mathrm{~mA} \mathrm{~cm}^{-2}$ in tartrate solution. The outer layer is composed of $\mathrm{H}, \mathrm{N}, \mathrm{C}$, and $\mathrm{O}$, which may correspond to the PPy layer doped by tartrate ions, $\mathrm{C}_{4} \mathrm{H}_{4} \mathrm{O}_{6}^{2-}$. It is notified that no zinc is found in the outer layer. Zinc appears in the deeper part. Although we cannot explain why the intensities of $\mathrm{C}, \mathrm{H}$, and $\mathrm{N}$ reveals peaks in this part on the depth profile, this part may indicate the inner layer consisting of zinc tartrate.

Figure 7 shows GD-OES depth profile of the PPy coat-
(A) $15 \mathrm{~mA} \mathrm{~cm} \mathrm{~cm}^{-2}$

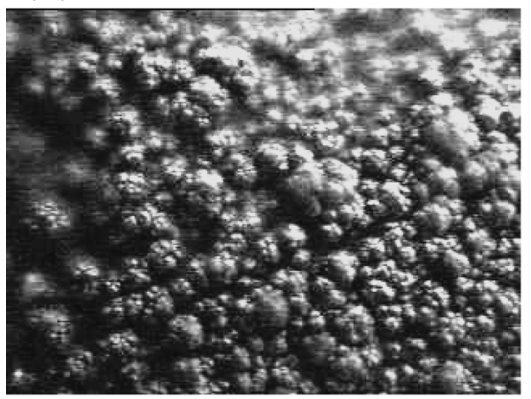

(B) $15 / 1 \mathrm{~mA} \mathrm{~cm}^{-2}$

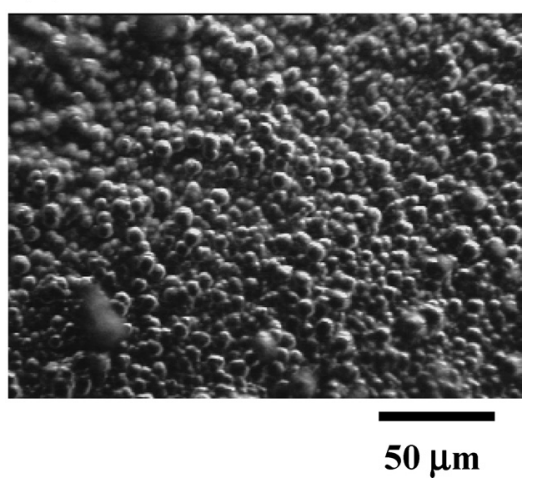

Fig. 4. Optical microscopic view of the PPy coated zinc. The PPy layer was formed in $0.2 \mathrm{M}$ tartrate solution containing $5 \mathrm{mM}$ molybdate and $0.5 \mathrm{M}$ pyrrole monomer (A) by one-step oxidation at $15 \mathrm{~mA} \mathrm{~cm} \mathrm{~cm}^{-2}$ for $300 \mathrm{~s}$ and (B) by two-step oxidation at $15 \mathrm{~mA} \mathrm{~cm}^{-2}$ for $100 \mathrm{~s}$ and then at $1.0 \mathrm{~mA} \mathrm{~cm}^{-2}$ for $3000 \mathrm{~s}$.

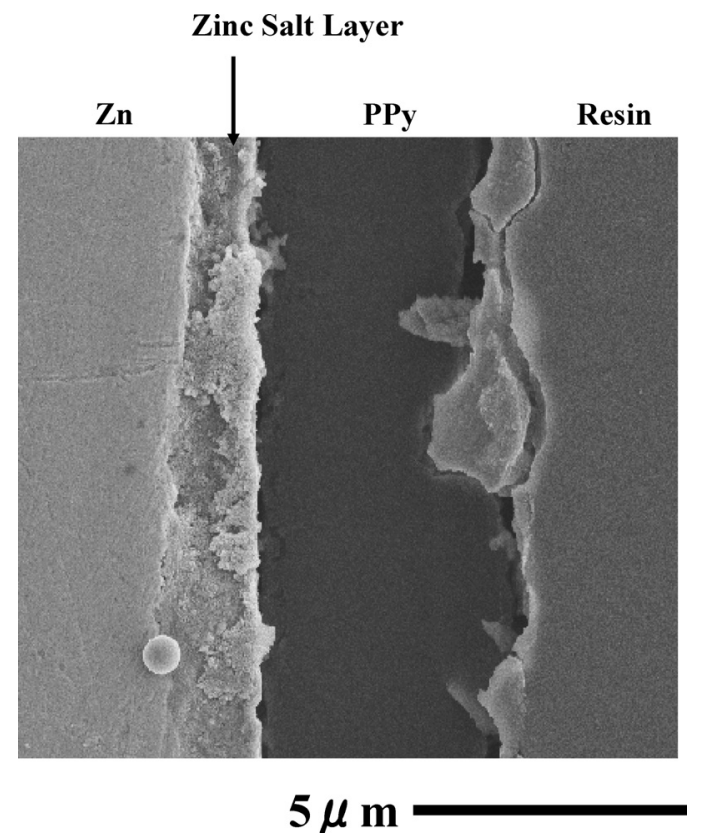

Fig. 5. Cross-sectional SEM view of PPy coating formed on zinc in the tartrate solution at $15 \mathrm{~mA} \mathrm{~cm}^{-2}$ for $300 \mathrm{~s}$.

ing formed in tartrate solution containing sodium molybdate. The depth profile is almost similar as that in Fig. 6, except for presence of molybdenum and shorter sputtering time period of the inner layer. The presence of molybdenum indicates that molybdate ions are doped into the charged PPy matrix with tartrate ions during the constant current polymerization. The shorter sputtering time, i.e., the thinner 


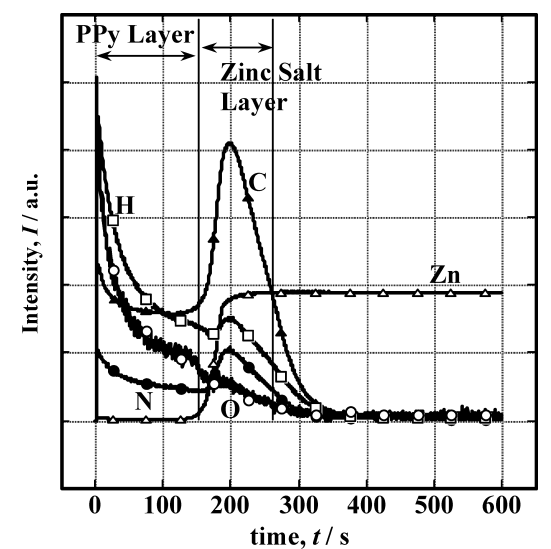

Fig. 6. GD-OES depth profile of the PPy coated zinc. The PPy coating was formed in tartrate solution at $15 \mathrm{~mA} \mathrm{~cm}^{-2}$ for $300 \mathrm{~s}$.

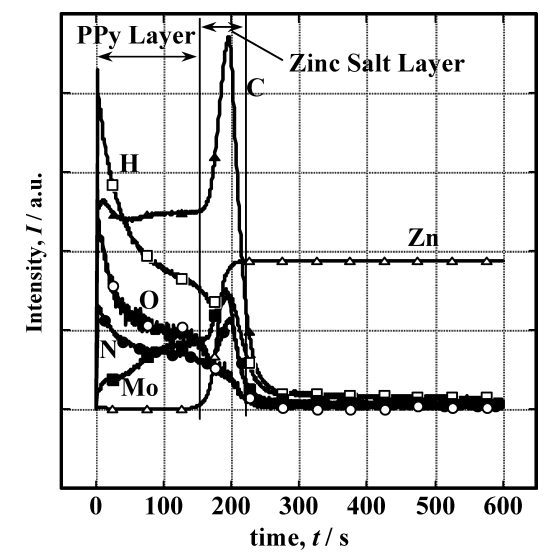

Fig. 7. GD-OES depth profile of the PPy coated zinc. The PPy coating was formed in tartrate solution containing $5 \mathrm{mM}$ sodium molybdate at $15 \mathrm{~mA} \mathrm{~cm}^{-2}$ for $300 \mathrm{~s}$.

inner layer of zinc salt layer is in agreement with the shorter time period of potential plateau before the PPy nucleation, as shown in Fig. 3. The intensities of $\mathrm{C}, \mathrm{H}$, and $\mathrm{N}$ as well as Mo also reveals maximum in the inner layer. Although the intensities and depth profile do not directly reflect the composition ratio and thickness, the compositional ratio will be estimate by introduction of concentration-tointensity calibration. We did not estimate the detail composition of the PPy coating; however, it is suggested that the molybdate anions are incorporated in the outer PPy layer as doped counter ions and are included in the inner salt layer as zinc molybdate.

The PPy is well known as electronic conductor. To confirm the conductivity, the $\mathrm{AC}$ impedance was measured by using two gold electrodes pressed to the PPy coated zinc electrode from the both sides. The AC impedance of the PPy coated zinc electrodes is shown in Fig. 8, in which the imaginary part of impedance is plotted against the real part as a parameter of frequency (the Nyquist plot). The PPy coatings were made by three preparations; $15 \mathrm{~mA} \mathrm{~cm}^{-2}$ for $300 \mathrm{~s}$ in the tartrate solution, $15 \mathrm{~mA} \mathrm{~cm}^{-2}$ for $300 \mathrm{~s}$ in the tartrate solution containing sodium molybdate, and $15 \mathrm{~mA} \mathrm{~cm}^{-2}$ for $100 \mathrm{~s}$ followed by $1 \mathrm{~mA} \mathrm{~cm}^{-2}$ for $3000 \mathrm{~s}$ in the tartrate solution containing sodium molybdate. For the impedance response shown in Fig. 8, we assumed the equivalent circuit indicated in Fig. 9, where the outer con-

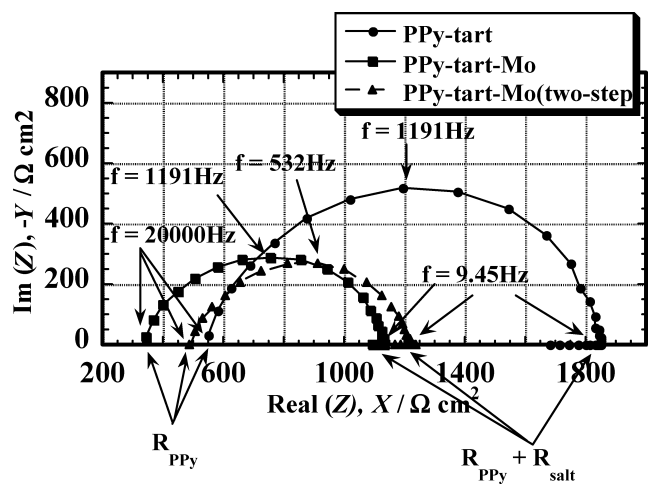

Fig. 8. Nyquist plot of impedance of the PPy-coated zinc. The PPy coating was prepared at $15 \mathrm{~mA} \mathrm{~cm}^{-2}$ for $300 \mathrm{~s}$ in the tartrate solution (PPy-tart), $15 \mathrm{~mA} \mathrm{~cm}^{-2}$ for $300 \mathrm{~s}$ in the tartrate solution containing sodium molybdate (PPy-tart$\mathrm{Mo}$ ), and $15 \mathrm{~mA} \mathrm{~cm}^{-2}$ for $100 \mathrm{~s}$ followed by $1 \mathrm{~mA} \mathrm{~cm}^{-2}$ for $3000 \mathrm{~s}$ in the tartrate solution containing sodium molybdate (PPy-tart-Mo(two-step)).

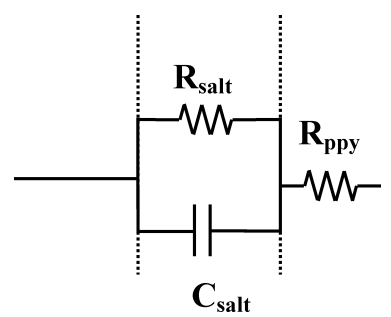

Fig. 9. Equivalent circuit of impedance for the PPy-coated zinc electrode. $\mathrm{R}_{\text {salt }}$ and $\mathrm{C}_{\text {salt }}$ is for the inner salt layer and $\mathrm{R}_{P P Y}$ for the outer PPy layer.

Table 2. Values of resistance and capacitance estimated from the equivalent circuit in Fig. 9 for the PPy coating formed by constant electricity of $4.5 \mathrm{C} \mathrm{cm}^{-2}$.

\begin{tabular}{|c|c|c|c|c|c|}
\hline Imposed CD & Solution & $\mathrm{R}_{\text {PPy }}$ & $\mathrm{R}_{\text {salt }}$ & $\mathrm{C}_{\text {salt }}$ & Thickness* \\
\hline $\mathrm{i} / \mathrm{mA} \mathrm{cm}^{-2}$ & & $\Omega \mathrm{cm}^{2}$ & $\Omega \mathrm{cm}^{2}$ & $10^{7} \mathrm{~F} \mathrm{~cm}^{-2}$ & $\mathrm{~d} / \mathrm{nm}$ \\
\hline 15 & Tartrate & 274 & 575 & 0.56 & 316 \\
\hline 15 & Tartrate + Molybdate & 170 & 395 & 0.89 & 200 \\
\hline $15 / 1.0^{\#}$ & Tartrate + Molybdate & 232 & 385 & 1.95 & 94 \\
\hline
\end{tabular}

*Estimated from capacitance value with assumption of $\varepsilon=20$.

${ }^{\#} 15 \mathrm{~mA} \mathrm{~cm}^{-2}$ for $100 \mathrm{~s}$ followed by $1.0 \mathrm{~mA} \mathrm{~cm}^{-2}$ for $3000 \mathrm{~s}$.

ducting PPy layer was connected with the inner dielectric layer of salt film. From Fig. 8, the resistance of the outer layer is estimated from a high frequency limit and the total resistance of the outer and inner layers from a low-frequency limit. The capacitance of the inner dielectric layer may be estimated from a frequency, $f_{0}$, at which the impedance occupies a top of the semicircle; $C_{\text {salt }}=\left(2 \pi f_{0} R_{\text {salt }}\right)^{-1}$. Table 2 shows circuit elements of $R_{\mathrm{PPy}}, R_{\text {salt }}$, and $C_{\text {salt }}$ estimated from the impedance and the equivalent circuit. The thickness of the salt layer $(d)$ in Table 2 was calculated from the capacitance value, $C_{\text {salt }}$.

$$
d=\varepsilon \varepsilon_{0} / C_{\text {salt }}
$$

where $\varepsilon$ is dielectric constant of the salt layer with assumption of $\varepsilon=20$, and $\varepsilon_{0}$ is vacuum permittivity. The thickness 


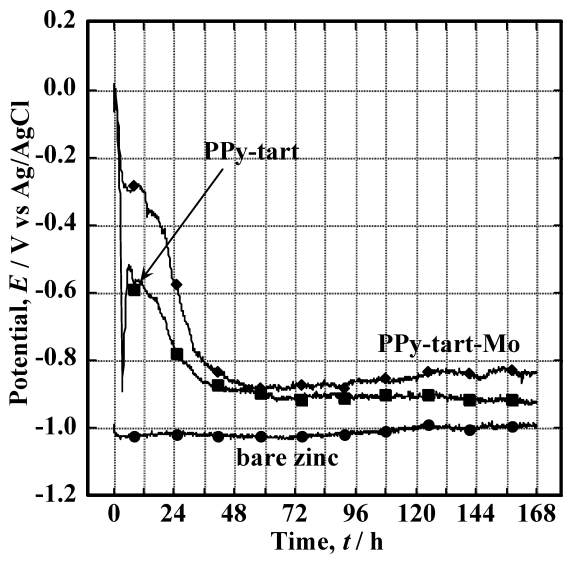

Fig. 10. Change in corrosion potential of bare zinc and the PPycoated zinc with time during immersion in $3.5 \mathrm{wt} \%$ $\mathrm{NaCl}$ solution. The PPy coating was prepared at $15 \mathrm{~mA} \mathrm{~cm}^{-2}$ for $100 \mathrm{~s}$ followed by $1 \mathrm{~mA} \mathrm{~cm}^{-2}$ for $3000 \mathrm{~s}$ in the tartrate solution (PPy-tart) and in the tartrate solution containing sodium molybdate (PPy-tartMo).

of the salt layer formed in the tartrate solution containing molybdate is smaller than that in the tartrate without molybdate. The resistance of the PPy layer formed in the tartrate solution containing molybdate is smaller than that in the tartrate without molybdate.

\subsection{Immersion in $\mathrm{NaCl}$ Solution of the PPy-coated Zinc}

Corrosion test of the PPy-coated zinc was made for $7 \mathrm{~d}$ in $3.5 \mathrm{wt} \%$ sodium chloride solution. During the test, corrosion potential was monitored. The results are given in Fig. 10, where the potential for bare zinc and the PPy coated zinc electrodes was plotted against time. The PPy coatings were made by the two-step polymerization at $\mathrm{CD}$ of $15 \mathrm{~mA} \mathrm{~cm}^{-2}$ for $100 \mathrm{~s}$ followed by $1.0 \mathrm{~mA} \mathrm{~cm}^{-2}$ for $3000 \mathrm{~s}$ in the tartrate solution with and without sodium molybdate. The bare zinc initially decreases to $-1.0 \mathrm{~V}$ vs. $\mathrm{Ag} / \mathrm{AgCl} /$ saturated $\mathrm{KCl}$ and keeps the potential during the immersion. White precipitate appears on the bare zinc immediately after the immersion. The zinc electrode coated by PPy layer which was formed in the tartrate solution exhibits a relatively high potential at the initial $36 \mathrm{~h}$ and the zinc electrode covered by PPy layer formed in the tartrate solution containing sodium molybdate keeps the high potential for the longer time period of $48 \mathrm{~h}$. During the initial time period, no precipitate appears on the coated zinc; zinc may be passivated by the salt passive layer underneath the PPy coating. The salt passive layer may be maintained with the help of the oxidative property of the outer PPy layer. The appreciable corrosion accompanied by white precipitate starts after the potential falls down to a range between -0.85 and $-0.9 \mathrm{~V}$.

\section{Discussion}

\subsection{Preparation of the PPy Coating}

Zinc is very active metal and the anodic polarization by constant current initially induces active dissolution. For polymerization of PPy, the potential should reach high potential enough to start nucleation of PPy. For realizing the high potential, the active dissolution must be moved to a state in which zinc is covered by oxide or salt layer. We tried to prepare the PPy layer on zinc in various aqueous solutions listed in Table 1. In acidic solution and organic salt solutions, the active dissolution continued and did not reach the high potential enough for polymerization to start. In neutral and alkaline phosphate, borate, and molybdate solutions, the potential could be risen due to stable salt and oxide layers which caused continuous increase of potential over $3 \mathrm{~V}$ until the reaction of oxygen evolution took place. In this case, the surface was covered by thick salt layer and oxide film, however, no PPy layer was observed on zinc electrode. Successful polymerization of PPy was only made in sodium tartrate solution containing or not small amount of sodium molybdate. In the solutions, anodic polarization at constant current higher than $10 \mathrm{~mA} \mathrm{~cm}^{-2}$ initially induces formation of a salt layer of zinc tartrate. During the salt layer formation, the potential is kept between -0.8 to $-0.7 \mathrm{~V}$. When the tartrate solution contained $20 \mathrm{mM}$ sodium molybdate, the potential plateau of the salt layer formation revealed the potential higher than that in the tartrate solution without molybdate. During the potential plateau, a mixed salt layer including zinc tartrate and zinc molybdate may be formed. The second plateau was observed at about $0.25 \mathrm{~V}$ before the PPy nucleation in the tartrate solution containing molybdate. From comparison with the polarization in molybdate solution, the second plareau is assumed to correspond to formation of a salt layer of zinc molybdate. The PPy later was started to form on the salt layer after revealing the potential peak at which nucleation of PPy took place. The salt layer thus formed may play an important role on protection of zinc in sodium chloride solution. We believe that the layer functions as a passivation layer of zinc and protects zinc substrate against corrosion.

The PPy coating formed is considered as the following layer structure; the inner salt layer consisting of zinc tartrate or zinc tartrate/molybdate, and the outer PPy layer doped by tartrate anions or tartrate/molybdate anions. The layer structure is coincident with the depth profile measured by GD-OES, as shown in Figs. 6 and 7. The doping ratio of tartrate/molybdate anions to the number of Py units would possibly be amounted by the detail composition which could be estimated by GD-OES analysis. However, we did not succeed the evaluation of the detail composition, because the calibration of the concentration to intensity of GD-OES signals was not done. Since it was proposed that an anion with one negative valence was doped to three or four Py units, ${ }^{18)}$ a tartrate or molybdate anion with bivalence may be doped to six to eight Py units.

From the AC impedance, the PPy layer is found to consist of the conductive and dielectric layers corresponding to the outer PPy and inner salt layers, respectively. The conductivity of the outer PPy layer increases with additional doping of molybdate anions to tartrate anions. The inner salt layer which was formed before the formation of the PPy layer reveals a dielectric property. The molybdate anions added into the tartrtate solution induces the thinner salt layer including zinc molybdate, resulting in the smaller resistance and the larger capacitance, which was shown in Fig. 8 and Table 2. The salt layer thickness may be in a region from a few hundreds $\mathrm{nm}$, as estimated by the capaci- 
tance value, to $1 \mu \mathrm{m}$, as estimated from the cross-sectional SEM view.

\subsection{Corrosion Protection of Zinc by PPy Layer in NaCl Solution}

The zinc electrode covered by the PPy layer revealed a potential in the passive region during the initial immersion in $\mathrm{NaCl}$ solution, as shown in Fig. 10. The zinc electrode was not corroded in the time period where the potential was kept in the passive region. The white corrosion products started to appear after the potential fell down to potential in the active region.

The salt layer on zinc functions as a passivation film and protects the substrate zinc. The PPy layer consists of positively charged PPy matrix and counter anions doped in the matrix. The positively charged PPy matrix supports maintenance of the passive layer due to its oxidative power.

$$
\mathrm{PPy}^{n+}+n \mathrm{e}=\mathrm{PPy}^{0}
$$

Without this support, the salt layer can not maintains the passivation of zinc. The positively charged PPy matrix gradually degrades with the following reaction, accompanied by release of doped anion in the PPy layer into the aqueous solution.

$$
\mathrm{PPy}^{n+} m \mathrm{~A}^{p-}+p \mathrm{e}=\mathrm{PPy}^{(n-p)+}(m-1) \mathrm{A}^{p-}+\mathrm{A}^{p-} \text { aq. }
$$

Both the salt layer and the oxidative PPy layer may, therefore, be essential to passivating of zinc. The molybdate included in the zinc salt layer and doping in the PPy layer may play a role for the enhancement of protection.

\section{Conclusion}

The polypyrrole coating was prepared on zinc electrode from sodium tartrate solution containing pyrrole monomer.

(1) The coating consisting of inner salt layer of zinc tartrate and outer PPy layer introduces passivation of zinc and protects zinc against corrosion in aqueous $\mathrm{NaCl}$ solu- tion.

(2) The molybdate added in the tartrate solution induces a thinner salt layer including zinc molybdate and a more conductive PPy layer doped by molybdate anions. The coating thus formed in the solution containing molybdate reveals a more ability of corrosion protection of zinc.

\section{Acknowledgement}

The present work was partially supported by ISIJ Research Promotion Grant of the Iron and Steel Institute of Japan.

\section{REFERENCES}

1) D. W. DeBerry: J. Electrochem. Soc., 132 (1985), 1022.

2) M. A. Malik, M. T. Galkowski, H. Bala, B. Grzybowska and P. J. Kulesza: Electrochim. Acta, 44 (1999), 2157.

3) R. Gasparac and C.-R. Martin: J. Electrochem. Soc., 148 (2001), B138.

4) R. Gasparac and C.-R. Martin: J. Electrochem. Soc., 149 (2002), B409.

5) W. Su and J. O. Iroh: Electrochem. Acta, 42 (1997), 2685.

6) M. Kraljic, Z. Mandic and L. Duic: Corros. Sci., 45 (2003), 181.

7) K. M. Cheung, D. Bloor and G. C. Stevens: Polymer, 29 (1988), 1709.

8) M. Schirmeisen and F. Beck: J. Appl. Electrochem., 19 (1989), 401.

9) A. M. Fenelson and C. B. Breslin: Electrochim. Acta, 47 (2002), 4467.

10) M. Bazzaoui, L. Martin, E. A. Bazzoui and J. I. Martin: J. Electroanal. Chem., 537 (2002), 47.

11) D. E. Tallman, C. Vang, G. G. Wallace and G. P. Bierwagen: J. Electrochem. Soc., 149 (2002), C173.

12) Z. Deng, W. H. Smyrl and H. White: J. Electrochem. Soc., 136 (1989), 2152.

13) A. M. Fenelon and C. B. Breslin: Corros. Sci., 45 (2003), 2837.

14) B. Zaid, S. Aeiyach, P. C. Lacaze and H. Takenouchi: Electrichim. Acta, 43 (1998), 2331.

15) J. Petitjean, S. Aeiyach, J. C. Lacroix and P. C. Lacaze: J. Electroanal. Chem., 478 (1999), 92.

16) J. M. Martins, T. C. Reis, M. Bazzaoui, E. A. Bazzaoui and L. Martines: Corrosion Sci., 46 (2004), 2361.

17) T. Ohtsuka, M. Iida and M. Ueda: J. Solid State Electrochem., 10 (2006), 714.

18) M. Takahashi, T. Tsuchida and T. Ohtsuka: Thin Solid Films, 280 (1996), 124. 